\title{
Head capsule stacking by caterpillars: morphology complements behaviour to provide a novel defence
}

Petah A Low, Clare McArthur, Dieter F Hochuli

Herbivores employ a variety of chemical, behavioural and morphological defences to reduce mortality from natural enemies. In some caterpillars the head capsules of successive instars are retained and stacked on top of each other and it has been suggested that this could serve as a defence against natural enemies. We tested this hypothesis by comparing the survival of groups of the gumleaf skeletoniser Uraba lugens Walker caterpillars, allocated to one of three treatments: "-HC", where stacked head capsules were removed from all individuals, " $+\mathrm{HC}$ ", where the caterpillars retained their stacked head capsules, and "mixed", where only half of the caterpillars in a group had their stacked head capsules removed. We found no difference in predation rate between the three treatments, but within the mixed treatment, caterpillars with head capsules were more than twice as likely to survive. During predator choice trials, conducted to observe how head capsule stacking acts as a defence, the predatory pentatomid bug attacked the $-\mathrm{HC}$ caterpillar in four out of six trials. The two attacks on $+\mathrm{HC}$ caterpillars took over 10 times longer because the bug would poke its rostrum through the head capsule stack, while the caterpillar used its head capsule stack to deflect the bug's rostrum. Our results support the hypothesis that the retention of moulted head capsules by $U$. Iugens provides some protection against their natural enemies and suggest that this is because stacked head capsules can function as a false target for natural enemies as well as a weapon to fend off attackers. This represents the first demonstration of a defensive function. 


\section{Head capsule stacking by caterpillars: morphology complements}

\section{2 behaviour to provide a novel defence}

3

4

5 Petah A. Low ${ }^{1}$, Clare McArthur ${ }^{1}$, and Dieter F. Hochuli ${ }^{1}$

$6{ }^{1}$ School of Biological Sciences, The University of Sydney, Sydney, N.S.W. 2006, Australia

9 Corresponding author:

Petah A. Low

11 Heydon-Laurence Building, The University of Sydney, Sydney, NSW, 2006, Australia

12 petah.low@sydney.edu.au

\section{Running title}

Head capsule stacking as a defence 
20 Abstract

21 Herbivores employ a variety of chemical, behavioural and morphological defences to reduce

22 mortality from natural enemies. In some caterpillars the head capsules of successive instars are

23 retained and stacked on top of each other and it has been suggested that this could serve as a

24 defence against natural enemies. We tested this hypothesis by comparing the survival of groups

25 of the gumleaf skeletoniser Uraba lugens Walker caterpillars, allocated to one of three

26 treatments: "-HC", where stacked head capsules were removed from all individuals, "+HC",

27 where the caterpillars retained their stacked head capsules, and "mixed", where only half of the

28 caterpillars in a group had their stacked head capsules removed. We found no difference in

29 predation rate between the three treatments, but within the mixed treatment, caterpillars with

30 head capsules were more than twice as likely to survive. During predator choice trials, conducted

31 to observe how head capsule stacking acts as a defence, the predatory pentatomid bug attacked

32 the $-\mathrm{HC}$ caterpillar in four out of six trials. The two attacks on $+\mathrm{HC}$ caterpillars took over 10

33 times longer because the bug would poke its rostrum through the head capsule stack, while the

34 caterpillar used its head capsule stack to deflect the bug's rostrum. Our results support the

35 hypothesis that the retention of moulted head capsules by U. lugens provides some protection

36 against their natural enemies and suggest that this is because stacked head capsules can function

37 as a false target for natural enemies as well as a weapon to fend off attackers. This represents the

38 first demonstration of a defensive function. 
41

42

43

44

45

46

47

48

\section{Introduction}

Natural enemies strongly influence the survival and fitness of insect herbivores and consequently are thought to have played a significant role in their evolution (Price et al. 2011; Schoonhoven et al. 2005). Caterpillars in particular are heavily preyed upon by a huge array of true predators, both vertebrate and invertebrate, and are host to a diversity of parasitic arthropods (Scoble 1992). In response, caterpillars have evolved a variety of ways to reduce mortality from natural enemies, including chemical, behavioral and morphological defenses (Stamp \& Casey 1993). For instance, many caterpillars possess defensive glands, emit offensive odors or sequester chemicals from their host plants to make themselves toxic or unpalatable (Bowers 1993; Bowers 2003). A range of behaviors can also form part of their defensive repertoire. Examples include resting on the underside of leaves, the building and use of refuges (Tvardikova \& Novotny 2012), removing evidence of their presence by throwing frass (Weiss 2003) or clipping damaged leaves (Edwards \& Wanjura 1989; Heinrich \& Collins 1983; Weinstein 1990), feeding gregariously (McClure \& Despland 2011; Reader \& Hochuli 2003), reducing activity (Thaler \& Griffin 2008), emitting startle or warning sounds such as clicking or whistling (Brown et al. 2007; Bura et al. 2011), regurgitating gut contents (Grant 2006), and thrashing, rearing or dropping from the plant (Allen 1990a; Castellanos et al. 2011; Low et al. 2014). Morphological defenses are also pervasive and include modifications for crypsis or camouflage such as shape disruption, color matching and counter-shading (Hossie \& Sherratt 2012; Rowland et al. 2008; Stamp \& Wilkens 1993), aposematic coloration (Bernays \& Montllor 1989), as well as the presence of protective hairs or spines (Murphy et al. 2010). 
63 Understanding how prey defences interact with and influence the foraging of natural enemies is

64 key to understanding the process of predation, and ultimately to understanding the crucial role

65 that natural enemies play in regulating populations of insect herbivores and preventing the

66 depletion of plant resources. Defences are thought to increase prey survival in the presence of

67 natural enemies. In the past, the study of defence has largely been anecdotal and based on

68 intuitive and subjective interpretations (Malcolm 1992; Scoble 1992), and consequently, in many

69 cases the evidence for a defensive strategy is purely circumstantial (Malcolm 1992; Scoble 1992). However, more recently there have been a growing number of rigorous and objective experimental studies that actually demonstrate a defensive function (e.g. Castellanos et al. 2011).

In some nolid caterpillars (Lepidoptera: Nolidae), the head capsules of successive instars are retained and stacked on top of each other above the head, a peculiar behaviour or developmental phenomenon which has been recorded in a number of species throughout the old world including Mimerastria mandshuriana in Japan, Roeselia togatulalis and R. nitida in Europe, Rhynchopala argentalis in India and the Australian native Uraba lugens (McFarland 1980; Fig. 1). It has been suggested that the stack of moulted head capsules could act as a defence, for instance by providing a false target for predators (McFarland 1980; Scoble 1992). In addition to this “decoy mechanism" (which has also been referred to as a divertive or deflective effect), the head capsules could make the caterpillar appear larger or more formidable to a potential predator

82 ("illusion mechanism") or be used in combination with thrashing and rearing behaviours to fend off enemies, including those attacking from behind ("lance mechanism"). Indeed, U. lugens often rear and thrash in response to simulated attack (Low et al. 2014) and actual attack (Allen 1990a), behaviours which are known to reduce the likelihood of being parasitized (Allen 1990a). 
86 However, these hypotheses have not been tested and therefore the purpose (if any) of retaining

87 moulted head capsules remains a mystery.

89 The gumleaf skeletoniser Uraba lugens has a wide distribution throughout Australia (Campbell 1962), feeding predominantly on myrtaceous tree species, including a variety of Eucalyptus and

91

92

93

94

106

Angophora species (Berndt \& Allen 2010). During the first four instars, feeding occurs gregariously with larvae skeletonizing leaves, while older larvae begin to disperse, feeding individually and consuming almost the entire leaf (Cobbinah 1978). Larvae go through a variable number of instars (usually 8-14) and retain their moulted head capsules from about the fifth instar (Berndt \& Allen 2010; Cobbinah 1978) (Fig. 1). Mature larvae grow to about 20-25 mm in length. They are well defended with urticating hairs which are thought to protect them from predation by birds (Allen 1990b). However, they are heavily attacked by a wide range of parasitic wasps and flies (Allen 1990b; Berndt \& Allen 2010; Farr 2002) as well as predatory bugs, jumping spiders and lacewings (Berndt \& Allen 2010).

We manipulated head capsule stacks on larvae to investigate the putative defensive function of head capsule stacking, testing the hypothesis that the retention of moulted head capsules by $U$. lugens caterpillars decreases rates of predation and parasitism in the field. We also aimed to investigate the mechanisms by which head capsule stacking could serve as a defence, through observations made during predator choice trials.

\section{Materials and methods}

Field observations 
109 We surveyed thirty natural groups of Uraba lugens larvae $\left(\sim 5^{\text {th }}-6^{\text {th }}\right.$ instar $)$ at our field site in

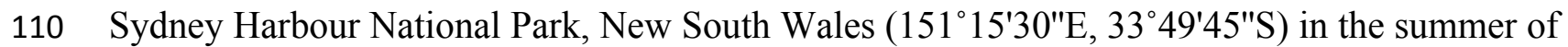

111 2013-2014. We recorded the number of individuals in each group and the number of head

112 capsules on each caterpillar. A caterpillar was considered to be part of a group if it was touching

113 or within a body length of another (Reader \& Hochuli 2003). We used these observations to

114 calculate the average number of caterpillars per group and assess head capsule distributions.

\section{Influence of stacked head capsules on rates of predation and parasitism}

117 We collected recently hatched $U$. lugens from our field site during the summer of 2013-2014 and took them back to the laboratory for rearing to minimize the chance of caterpillars being

119 parasitized before the experiment. The caterpillars were housed in plastic containers and kept in 120 a constant temperature room, maintained at $23 \pm 2{ }^{\circ} \mathrm{C}$ with approximately $90 \%$ humidity. They 121 were regularly provided with fresh foliage from Angophora floribunda (Sm.) Sweet, one of their

122 host plant species. When caterpillars reached approximately their fifth or sixth instar (larvae

123 about $10 \mathrm{~mm}$ long, with 2-3 head capsules), they were returned to the field. We set the 124 caterpillars on Angophora and Eucalyptus trees in groups of ten individuals, with each group 125 placed on a separate tree. This group size was chosen based on field observations of group sizes 126 for caterpillars of this stage. The groups were allocated to one of three treatments: "-HC", where 127 stacked head capsules were removed from all ten individuals, "+HC", where the caterpillars 128 retained their stacked head capsules, and "mixed", where five of the caterpillars had their stacked 129 head capsules removed and five retained their head capsule stack. The "mixed" treatment was 130 included to investigate any social dimension to the defence, in other words, whether the benefit 131 of head capsule stacks as a defence is dependent on "easier", less defended alternatives being 
132 available. The stacked head capsules were easily removed by gently lifting them from off the top

133 of the caterpillar's head using soft forceps, while holding the caterpillar down with a soft paint

134 brush. Caterpillars that retained their stacked head capsules experienced a similar level of

135 disturbance. We set twenty groups per treatment type and the host plant species used were evenly

136 represented among treatments. Further, we blocked replicates from each treatment in space to

137 minimise any effect of spatial variation in risk. Survival was monitored after four and eight days.

138 We were confident that caterpillars would be recovered if present because they leave obvious

139 signs of their presence in the form of feeding damage and moulted skins. On day four, we

140 removed any new head capsules from the relevant caterpillars. All caterpillars remaining at the

141 end of the eight days were collected and taken back to the laboratory. Here they were reared

142 through to adults ( $\sim 16$ weeks) to allow assessment of rates of parasitism. Caterpillars from each

143 replicate were housed separately in plastic containers in the CT room and fed A. floribunda

144 foliage.

We compared the survival of caterpillars from the different treatments using Cox proportional hazards analysis. We performed two analyses, one comparing survival between the $+\mathrm{HC}$ and $\mathrm{HC}$ group treatments, and a second comparing survival of $+\mathrm{HC}$ and $-\mathrm{HC}$ caterpillars within the mixed treatment. To control for the lack of independence of caterpillars within a group, we clustered the caterpillars by group in our analyses. Additionally, we stratified the analyses by

151 host plant to account for any differences in hazard rate between tree species, and stratified the 152 first analysis by replicate to account for the blocking of replicates. Statistical analyses were 153 performed using R version 3.2.3 (R Development Core Team 2015), and we tested the assumption of proportionality using the cox.zph function. . 
156 Field work was conducted under National Parks and Wildlife Services N.S.W. Scientific Licence

157 number SL100838.

158

159

\section{Observation of predation events}

160 To investigate possible mechanisms by which head capsule stacks serve as a defence, we 161 conducted predator choice trials. We used direct capture and beat sampling to collect potential 162 arthropod predators from the Eucalyptus and Angophora trees at our field site. We then used the 163 collected predators, which included various spiders (four Sparassidae, four Clubionidae, two

164 Thomisidae and two Salticidae) and one pentatomid bug (Cermatulus nasalis Woodward, 165 Pentatomidae), in predator choice trials. For the choice trials, we placed two caterpillars, in 166 approximately their $6^{\text {th }}$ instar and matched for size, into a Petri dish ( $9 \mathrm{~cm}$ diameter) with a single

167 eucalypt leaf lying flat on the base. One of the caterpillars had its stack of moulted head capsules 168 removed using soft forceps $(-\mathrm{HC})$, while the other retained its moulted head capsules but 169 received a similar amount of physical disturbance $(+\mathrm{HC})$. A single predator was then introduced 170 and given the choice of attacking either caterpillar. For spiders, we ran multiple trials

171 simultaneously, watching them for the first half hour and then filming with a video camera for

172 the rest of the 24 hours. We tested the pentatomid bug six times and these trials were also

173 watched and filmed. To increase their motivation for feeding, the spiders were starved for six

174 days prior to a trial, while the pentatomid bug was starved for at least two days between 175 successive trials. We recorded which caterpillar was attacked first $(-\mathrm{HC}$ or $+\mathrm{HC})$, where the 176 caterpillar was attacked (head, middle, abdomen), the caterpillar's responses to attack and 177 whether the attack was successful (i.e. prey killed). We also calculated attack duration, which for 
178 the pentatomid bug was defined as the time between when the bug extended its rostrum and 179 when the rostrum was successfully inserted into the caterpillar.

\section{Results}

Field observations

Uraba lugens larvae occurred in groups of varying size (1-47 individuals), though most

individuals and a median of 8 individuals (interquartile range $=5.75, \mathrm{n}=30$ groups). Most

the individuals within a single group often had the same number of head capsules, eight out of the thirty groups contained caterpillars with differing numbers of head capsules.

\section{Influence of stacked head capsules on rates of predation}

Overall there was a $16 \%$ survival rate, with only 96 of the 600 caterpillars placed in the field surviving the eight days. There was no statistically significant difference in survival between the caterpillars in the $+\mathrm{HC}$ and $-\mathrm{HC}$ treatment groups $(\mathrm{z}=3.96, \mathrm{df}=1, \mathrm{P}=0.05$; Fig. 3a). However within the mixed treatment, caterpillars with head capsule stacks were more than twice as likely to survive as those without $(\mathrm{z}=-2.83, \mathrm{df}=1, \mathrm{P}=0.005$; Fig. $3 \mathrm{~b})$. In many instances where no caterpillars remained after eight days, feeding damage and moulted skins on the leaves indicated that the caterpillars had settled and established themselves, and in more than $13 \%$ of the replicates there was direct evidence of predation (caterpillar remains, Fig. S1). 
201 Two types of parasitoid had attacked the caterpillars, a species of wasp from the family

202 Braconidae which emerged from the larval stage and a species of fly from the family Tachinidae

203 which emerged once the caterpillars had pupated. Of the $46-\mathrm{HC}$ caterpillars remaining at the

204 end of the field experiment, seven of these were parasitized ( $15 \%$ parasitism rate), three by

205 wasps and four by flies. In contrast, only two of the 50 surviving $+\mathrm{HC}$ caterpillars were

206 parasitized (4\% parasitism rate), both by flies.

207

208

Observation of predation events

209 None of the spiders attacked the caterpillars. The pentatomid bug, however, readily attacked

210

them, attacking the $-\mathrm{HC}$ caterpillar in four out of the six choice trials. In all six trials, the bug

211 attacked the head end of the caterpillar and eventually inserted its rostrum near the caterpillar's

212 head. When attacked, +HC and -HC caterpillars showed similar behavioural responses,

213 including thrashing, rearing their head, curling their body, regurgitating and walking away.

214 Attacks on $+\mathrm{HC}$ caterpillars took much longer ( $\geq 127$ seconds) than attacks on $-\mathrm{HC}$ caterpillars

215 ( $\leq 14$ seconds). During attacks on $+\mathrm{HC}$ caterpillars, the bug poked its rostrum into the head 216 capsule stack several times (Fig. 4a-c; see also Supplementary Video, e.g. 1:08, 1:15) and the

217 caterpillars used their head capsule stack to fend off the bug and deflect its rostrum (Fig. 4d-f;

218 Supplementary Video, e.g. 1:38, 1:54, 2:15, 2:37), all of which contributed to prolonging the

219 attack duration. Although varying in duration, all attacks were eventually successful.

Discussion

222 Our results support the hypothesis that the retention of moulted head capsules by Uraba lugens provides some protection against their natural enemies and suggest that this is at least partially 
224 because stacked head capsules can function as a false target for natural enemies as well as a 225 weapon to fend off some attackers.

226

227 Our field experiment confirmed predation as an important source of mortality for $U$. lugens

228 larvae, since the mortality rate was $84 \%$ over just 8 days $(\sim 1 / 4$ of their larval duration). Defences

229 are unlikely to be effective against the full suite of natural enemies in natural systems, and so

230 such high mortality levels are not surprising or unusual. However, greater survival of caterpillars

231 with head capsule stacks within our 'mixed' treatment groups and reduced levels of parasitism

232 among surviving $+\mathrm{HC}$ caterpillars, together provide some evidence that under certain conditions

233 head capsule stacking can be an effective defence, more than doubling a caterpillar's chance of

234 survival. That a difference in predation rate between caterpillars with and without their head

235 capsule stack was only found in the 'mixed' treatment groups, suggests a social dimension to the

236 defence; a caterpillar's vulnerability is influenced by the traits (i.e. the presence or number of

237 stacked head capsules) of other members of the group. Importantly, the observational component

238 of our study confirmed that under natural conditions caterpillars do occur in groups where

239 individuals have varying numbers of stacked head capsules, and therefore that it is realistic that

240 predators may have the opportunity to select between prey differing in their defence. The

241 observed differences in head capsule numbers could result from the loss of head capsules or

242 differences in the speed of development and timing of moulting. Although our study only

243 compared the presence and absence of head capsules, it will also be important to consider how

244 the number of stacked head capsules might influence the effectiveness of head capsule stacks as

245 a defence. 
247 Our field results also raise the possibility that predator type or the level of predation pressure

248 may be important in influencing the effectiveness of head capsule stacking as a defence. There

249 were some groups where survival was high and others where survival was poor, irrespective of

250 whether the caterpillars had stacked head capsules or not. This could suggest that, while

251 providing some level of protection, head capsules may not be equally effective against all

252 predators and are not sufficient to prevent predation by highly motivated predators. It is also

253 possible that when predation pressure is very high or very low, head capsules may not provide an

254 advantage. Rather, head capsule stacking may be most effective as a defence under intermediate

255 levels of predation pressure. Consequently we propose that small-scale spatial variation in

256 predation pressure may have contributed to the variable influence of head capsule stacking on

257 caterpillar survival seen in our study. Indeed in a similar study testing the effectiveness of the

258 fecal shields of tortoise beetle larvae as a defence against their predators, shields were found to

259 be least effective under low prey density, likely because when prey availability is low relative to

260 predator abundance (i.e. predation pressure is relatively high), hungry predators are less deterred

261 by prey defences and more persistent in their attacks (Olmstead \& Denno 1993).

262

263 Field experiments such as ours, comparing the survival of defended and undefended prey, are

264 rare but important because they allow examination in a natural setting of the effectiveness of a

265 defence against an entire complex of natural enemies. An assumption, though, is that

266 disappearance equates to predation. While it is possible that some of the disappearances of the

267 larvae could have alternative explanations, such as dropping off the leaf or dispersal, we are

268 confident that disappearance was largely the result of predation. Uraba lugens caterpillars leave

269 obvious signs of their presence, in the form of feeding damage and moulted skins, and for many 
270 groups where no larvae were recovered there was evidence that they had settled and become

271 established on the branches where they were set, making it unlikely that they just fell off the

272 plant or dispersed from the area. In other cases there was more direct evidence of predation, most

273 likely from spiders, which included drained bodies wrapped in silk and masticated remains

274 containing caterpillar hairs and in some cases intact head capsule stacks (Fig. S1). Further, there

275 is no reason to expect that there would be a systematic bias in rate of dispersal between our

276 treatments, suggesting that any difference can reasonably be attributed to predation.

277

278 The lack of predation by the various spiders during the predator choice trials was surprising given the evidence of spider predation in the field experiment. This was possibly because the spiders responsible for attacking the caterpillars in the field were not among those collected. Alternatively, the spiders may have needed more than 24 hours to set up webbing or establish hunting areas. The pentatomid bug, however, readily attacked the caterpillars. Although we lacked replicate bugs, the choice trials using the one bug showed that head capsule stacks can serve a defensive function. Additionally the trials did not provide evidence against any of the hypothesized mechanisms, but rather suggest that a combination of them could be operating. The tendency for the bug to attack the $-\mathrm{HC}$ individual more often than the $+\mathrm{HC}$ individual is consistent with the 'illusion mechanism', assuming the bug uses sight to select prey and that previous learning did not play a part. For instance, it is possible that the bug had learnt that prey with head capsules take longer to subjugate or are less likely to result in successful predation, and are therefore less profitable. Indeed there is a growing body of work showing that predatory

291 insects are capable of associative learning (e.g. Guillette et al. 2009). The substantially longer

292 duration of attacks for caterpillars with their head capsule stack intact suggests that head capsule 
293 stacks make it more difficult for the bug to subjugate the caterpillar. Importantly, the attacks on

294 the $+\mathrm{HC}$ caterpillars also provide evidence that the head capsule stack can act as a false target for

295 predators ('decoy mechanism') and as a weapon to fend off the bug and deflect it's rostrum

296 ('lance mechanism'), both extending the time taken for the bug to overcome the caterpillar.

297 Prolonging the duration of the attack and subjugation phases of predation (sensu Endler 1991)

298 may increase opportunity for escape or the likelihood that a predator will give up on the attack.

299 Even though all attacks by the bug were eventually successful, this should not be interpreted as

300 indicating that head capsules do not influence attack success. The experimental setup likely

301 restricted the effectiveness of caterpillar responses, since their confinement meant they could not

302 escape by dropping or walking away. Such responses to attack are common in U. lugens (Low et

303 al. 2014) and are known to be effective means of escaping predators (Castellanos et al. 2011).

304 Nevertheless, further predator choice trials testing a greater range of natural enemies would be

305 useful to confirm our preliminary conclusions regarding the mechanisms by which head capsule

306 stacking functions as a defence.

307

308 Our study suggests that head capsule stacking may be a very cost-effective way of deterring

309 natural enemies, given that no additional biosynthesis is required beyond what would ordinarily

310 occur in the animal. If there are indeed negligible costs to the retention of moulted head capsules,

311 this begs the question why the behaviour is not seen more often among caterpillars. It is possible

312 that there may be ecological or physiological costs if larvae with head capsules are more

313 conspicuous to certain predators or if there are energetic costs of carrying the head capsules.

314 Future work should investigate potential costs and consider the phylogenetic and ecological 
315 correlates of the trait to help to explain its occurrence and why it is not more widely observed

316 among caterpillars. 


\section{Acknowledgements}

319 Thanks to M. Low, D. Attard, R. Reid and A. Zhuo for help in the field, G. Cassis for

320 identification of the pentatomid bug and D. Britton for identification of the parasitoids. Thanks

321 also to Thomas Hossie, Mike Speed and an anonymous reviewer for helpful comments on the 322 manuscript.

\section{References}

325

Allen GR. 1990a. Influence of host behavior and host size on the success of oviposition of Cotesia urabae and Dolichogenidea eucalypti (Hymenoptera: Braconidae). Journal of Insect Behavior 3:733-749. 10.1007/bf01065962

Allen GR. 1990b. Uraba lugens Walker (Lepidoptera: Noctuidae): larval survival and parasitoid biology in the field in South Australia. Journal of the Australian Entomological Society 29:301-312.

Bernays EA, and Montllor CB. 1989. Aposematism of Uresiphita reversalis larvae (Pyralidae) Journal of the Lepidopterists' Society 43:262-273.

Berndt LA, and Allen GR. 2010. Biology and pest status of Uraba lugens Walker (Lepidoptera: Nolidae) in Australia and New Zealand. Australian Journal of Entomology 49:268-277. 10.1111/j.1440-6055.2010.00760.x

Bowers MD. 1993. Aposematic caterpillars: life-styles of the warningly colored and unpalatable. In: Stamp NE, and Casey TM, eds. Caterpillars Ecological and evolutionary constraints on foraging. New York: Chapman and Hall, 331-371. 
339 Bowers MD. 2003. Hostplant suitability and defensive chemistry of the Catalpa sphinx,

$340 \quad$ Ceratomia catalpae. Journal of Chemical Ecology 29:2359-2367.

341

10.1023/a:1026234716785

342 Brown SG, Boettner GH, and Yack JE. 2007. Clicking caterpillars: acoustic aposematism in Antheraea polyphemus and other Bombycoidea. Journal of Experimental Biology 210:993-1005. 10.1242/jeb.001990

Bura VL, Rohwer VG, Martin PR, and Yack JE. 2011. Whistling in caterpillars (Amorpha juglandis, Bombycoidea): sound-producing mechanism and function. Journal of Experimental Biology 214:30-37. 10.1242/jeb.046805

Campbell K. 1962. The biology of Roeselia lugens (Walk.), the gum-leaf skeletonizer moth, with particular reference to the Eucalyptus camaldulensis Dehn. (river red gum) forests of the Murray Valley Region. Proceedings of the Linnean Society of New South Wales 87:316338.

Castellanos I, Barbosa P, Zuria I, Tammaru T, and Christman MC. 2011. Contact with caterpillar hairs triggers predator-specific defensive responses. Behavioral Ecology 22:1020-1025. 10.1093/beheco/arr085

Cobbinah JR. 1978. The biology and food preferences of the gum leaf skeletonizer, Uraba lugens (Walk.). PhD Thesis. University of Adelaide.

Edwards PB, and Wanjura WJ. 1989. Eucalypt-Feeding Insects Bite Off More Than They Can Chew Sabotage of Induced Defenses. Oikos 54:246-248.

Endler JA. 1991. Interactions between predators and prey. In: Krebs JR, and Davies NB, eds. Behavioural Ecology An evolutionary Approach. Third ed. Oxford: Blackwell Scientific Publications, 169-196. 
362 Farr JD. 2002. Biology of the gumleaf skeletoniser, Uraba lugens Walker (Lepidoptera:

363

364

365

366

367

368

369

370

371

372

373

374

375

376

377

378

379

380

381

382

383

Noctuidae), in the southern jarrah forest of Western Australia. Australian Journal of Entomology 41:60-69.

Grant JB. 2006. Diversification of gut morphology in caterpillars is associated with defensive behavior. Journal of Experimental Biology 209:3018-3024. 10.1242/jeb.02335

Guillette LM, Hollis KL, and Markarian A. 2009. Learning in a sedentary insect predator: Antlions (Neuroptera: Myrmeleontidae) anticipate a long wait. Behavioural Processes 80:224-232. http://dx.doi.org/10.1016/j.beproc.2008.12.015

Heinrich B, and Collins SL. 1983. Caterpillar leaf damage, and the game of hide-and-seek with birds. Ecology 64:592-602.

Hossie TJ, and Sherratt TN. 2012. Eyespots interact with body colour to protect caterpillar-like prey from avian predators. Animal Behaviour 84:167-173.

10.1016/j.anbehav.2012.04.027

Low PA, McArthur C, and Hochuli DF. 2014. Dealing with your past: experience of failed predation suppresses caterpillar feeding behaviour. Animal Behaviour 90:337-343. http://dx.doi.org/10.1016/j.anbehav.2014.02.020

Malcolm SB. 1992. Prey defence and predator foraging. In: Crawley MJ, ed. Natural Enemies The population biology of predators, parasites and diseases. Oxford: Blackwell Scientific Publications, 458-475.

McClure M, and Despland E. 2011. Defensive responses by a social caterpillar are tailored to different predators and change with larval instar and group size. Naturwissenschaften 98:425-434. 10.1007/s00114-011-0788-X 
384 McFarland N. 1980. Retention of cast head capsules by some nolid immatures in four Old World 385 countries. Journal of research on the Lepidoptera 17:209-217.

386 Murphy SM, Leahy SM, Williams LS, and Lill JT. 2010. Stinging spines protect slug caterpillars 387 (Limacodidae) from multiple generalist predators. Behavioral Ecology 21:153-160.

388

389

390

391

392

393

394

395

396

397

398

399

400

401

402

403

404

405

\subsection{3/beheco/arp166}

Olmstead KL, and Denno RF. 1993. Effectiveness of Tortoise Beetle Larval Shields Against Different Predator Species. Ecology 74:1394-1405. 10.2307/1940069

Price PW, Denno RF, Eubanks MD, Finke DL, and Kaplan I. 2011. Insect Ecology: Behavior, Populations and Communities. Cambridge, UK: Cambridge University Press.

R Development Core Team 2015. R: A Language and Environment for Statistical Computing. Vienna, Austria: R Foundation for Statistical Computing. http://www.R-project.org.

Reader T, and Hochuli DF. 2003. Understanding gregariousness in a larval Lepidopteran: The roles of host plant, predation, and microclimate. Ecological Entomology 28:729-737.

Rowland HM, Cuthill IC, Harvey IF, Speed MP, and Ruxton GD. 2008. Can't tell the caterpillars from the trees: countershading enhances survival in a woodland. Proceedings of the Royal Society B: Biological Sciences 275:2539-2545. 10.1098/rspb.2008.0812

Schoonhoven LM, van Loon JJA, and Dicke M. 2005. Insect-Plant Biology. Oxford: Oxford University Press.

Scoble MJ. 1992. The Lepidoptera: Form, Function and Diversity. Oxford: Oxford University Press.

Stamp NE, and Casey TM. 1993. Caterpillars. Ecological and evolutionary constraints on foraging. New York: Chapman and Hall. 
406 Stamp NE, and Wilkens RT. 1993. On the cryptic side of life: being unapparent to enemies and 407 the consequences for foraging and growth of caterpillars. In: Stamp NE, and Casey TM, 408

409 eds. Caterpillars Ecological and evolutionary constraints on foraging. New York:

410

411

412

413

414

415

416

417

418

419

420

421 Chapman and Hall, 283-330.

Thaler JS, and Griffin CAM. 2008. Relative importance of consumptive and non-consumptive effects of predators on prey and plant damage: the influence of herbivore ontogeny. Entomologia Experimentalis et Applicata 128:34-40. 10.1111/j.1570-7458.2008.00737.x

Tvardikova K, and Novotny V. 2012. Predation on exposed and leaf-rolling artificial caterpillars in tropical forests of Papua New Guinea. Journal of Tropical Ecology 28:331-341. $10.1017 / \mathrm{s} 0266467412000235$

Weinstein P. 1990. Leaf Petiole Chewing and the Sabotage of Induced Defences. Oikos 58:231233.

Weiss MR. 2003. Good housekeeping: why do shelter-dwelling caterpillars fling their frass? Ecology Letters 6:361-370. 10.1046/j.1461-0248.2003.00442.x 


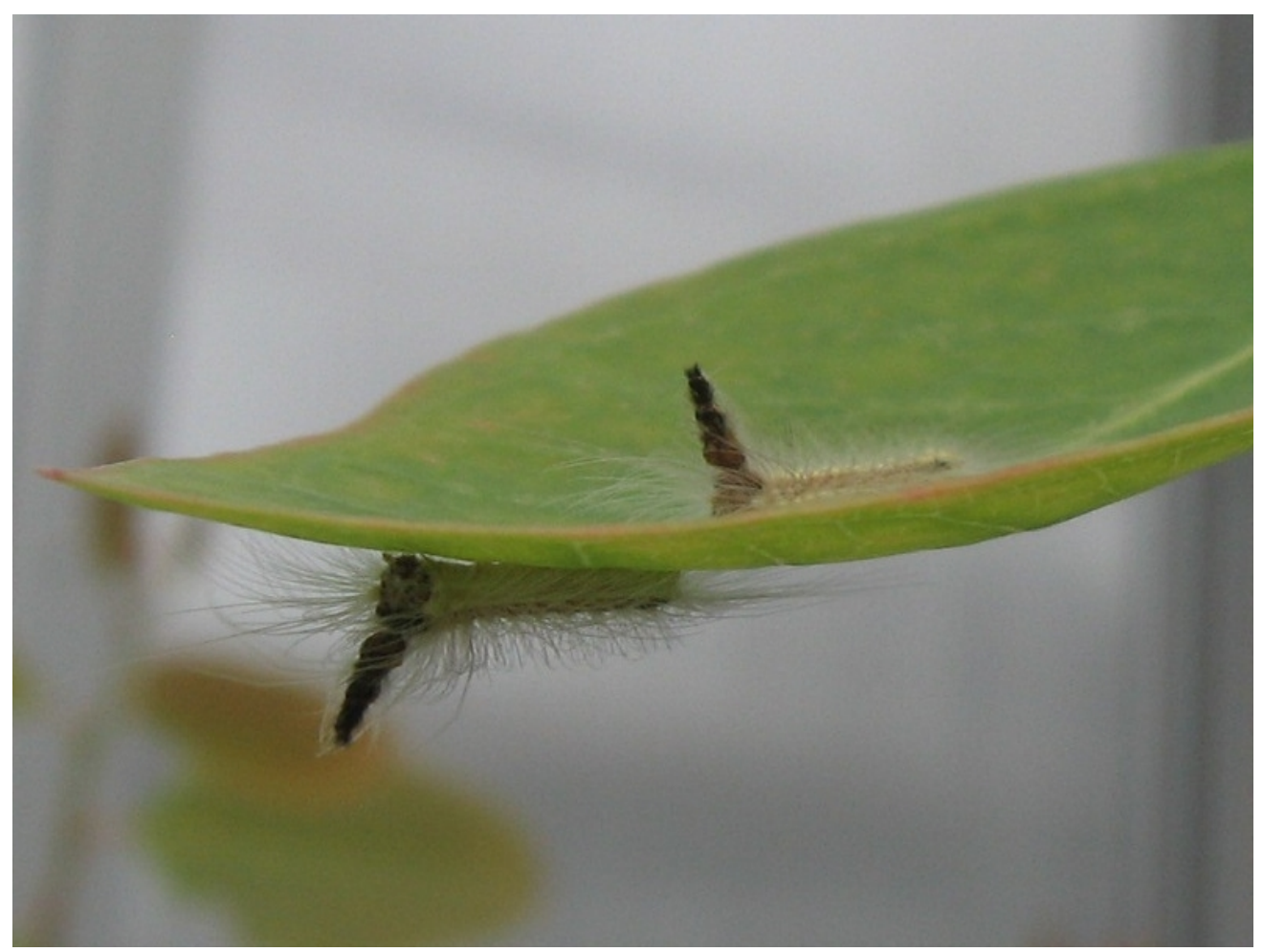

425 Fig. 1. Uraba lugens caterpillars (approximately sixth instar) with moulted head capsules stacked 426 above their heads. Photo: P. Low. 


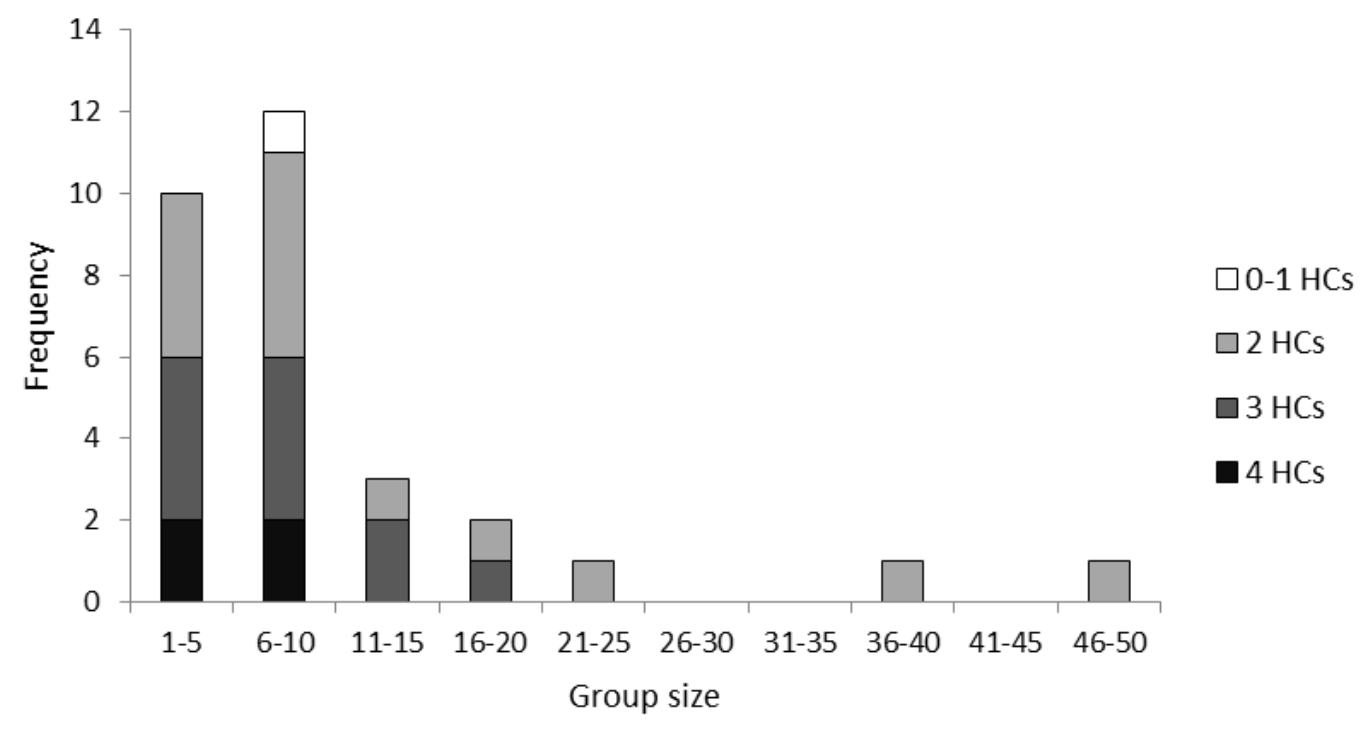

428

429 Fig. 2. The frequency of different group sizes for 30 groups of fifth-sixth instar Uraba lugens

430 caterpillars observed in the field. Shading indicates the dominant number of stacked head

431 capsules possessed by caterpillars in each group. 

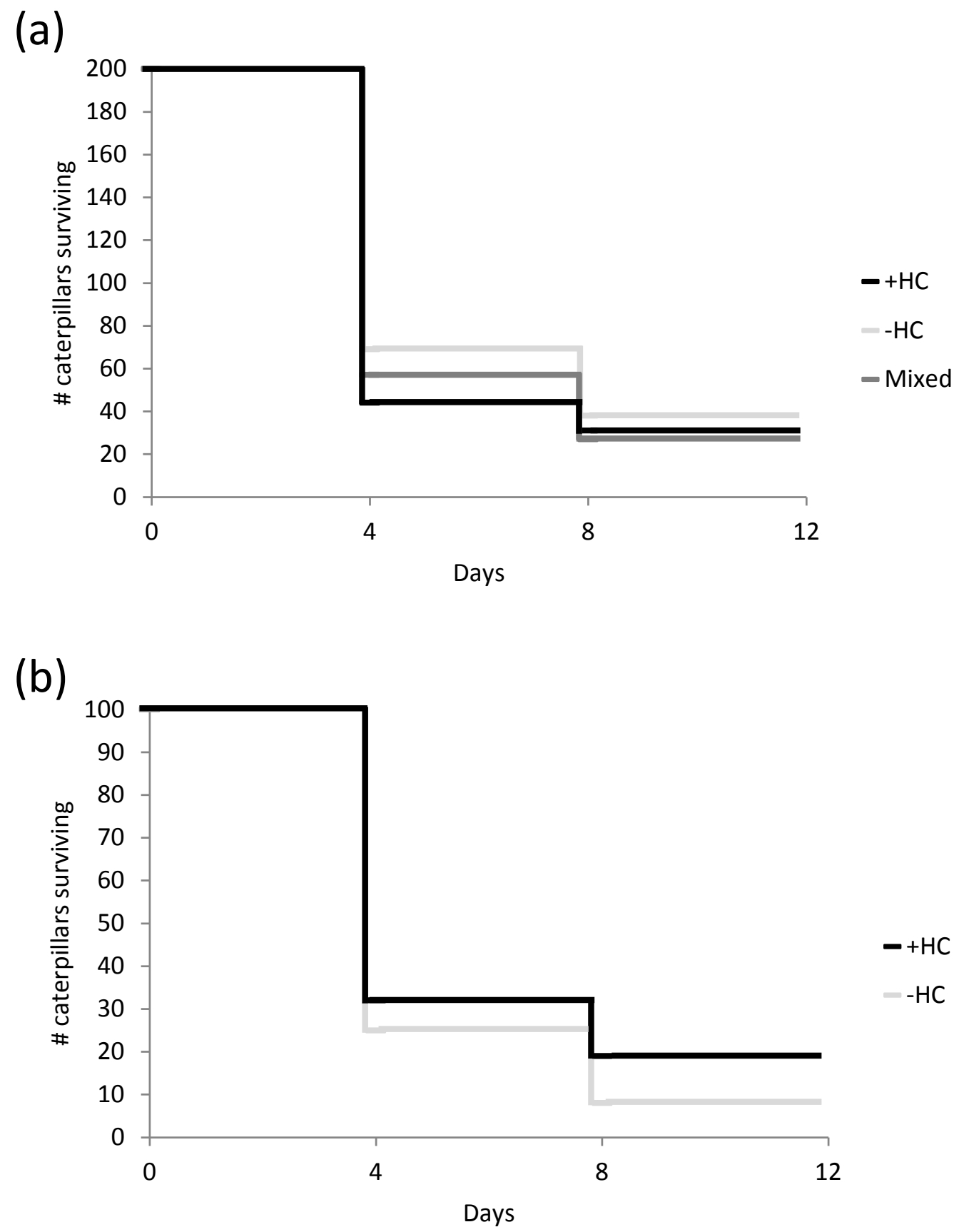

432

433 Fig. 3. (a) Survival of caterpillars from three treatments, $+\mathrm{HC}$ (head capsule stacks intact), $-\mathrm{HC}$ 434 (head capsule stacks removed), and mixed (head capsule stack removed from half of the group).

435 For each treatment, 200 caterpillars were set out in 20 groups consisting of 10 larvae. (b)

436 Survival of caterpillars within the mixed treatment. 


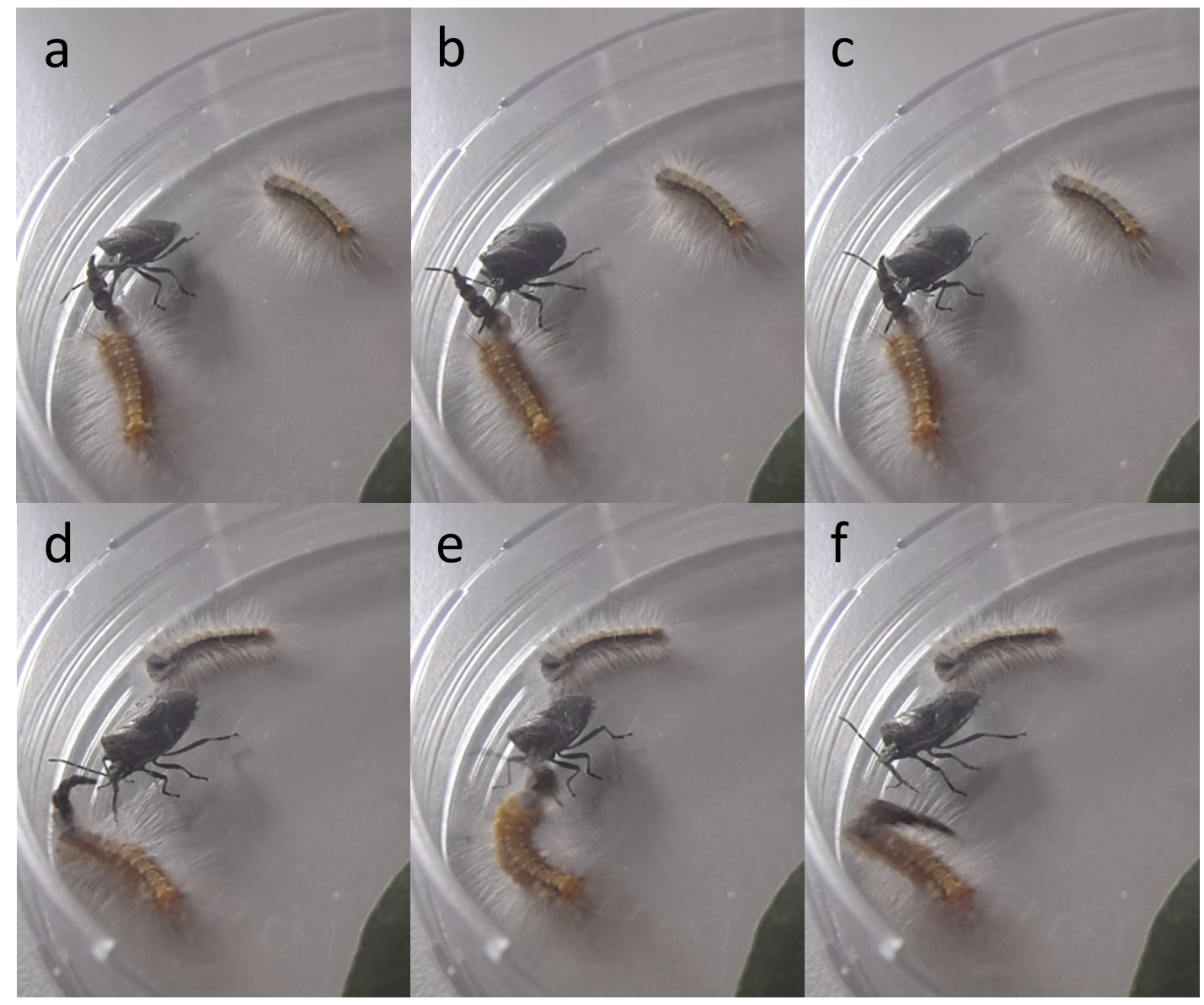

438 Fig. 4. Screen captures from a video of an attack by the pentatomid bug on a Uraba lugens

439 caterpillar, showing how the caterpillar uses its head capsule stack to defend itself; head capsule

440 stack (a-c) serving as a false target or decoy, (d-f) being used to deflect the bug's rostrum. For

441 the full video, see the supplementary material.

442 